Pausa entre Consultas

BetweEn ApPointments

Responsável: Saul Schaf

\title{
Órtese de Jeans para Desvio Ulnar dos Dedos
}

A articulação metacarpofalangeana (MCF) é comumente afetada na artrite reumatóide (AR), sendo sujeita a grande estresse durante movimentos constantes na função diária, como ao abrir e fechar potes e torneiras e ao picar alimentos utilizando-se faca. Com a progressão do processo reumatóide, o equilíbrio muscular normal é perdido e as estruturas do sistema ligamentar são atingidas, com conseqüente desenvolvimento de deformidades manifestadas por aumento do desvio ulnar. Uma vez ocorrido o desvio ulnar, as forças deformantes, desencadeadas por pressões externas (manuseio de objetos com movimentos na direção ulnar) e/ou internas (desequilíbrio das estruturas articulares e musculares) acentuarão a deformidade. As pressões que contribuem para padrões de deformidade devem ser evitadas. A órtese de desvio ulnar tem como objetivo promover aumento da função e neutralizar a tendência das articulações MCFs desviarem-se ulnarmente durante a preensão, promovendo também estabilidade articular ao compensar parcialmente a frouxidão ligamentar e capsular. A órtese promove tracionamento dos dedos para seu alinhamento central e assim reduz o desvio ulnar. Em razão da relação entre o uso da mão e o desenvolvimento dessa deformidade, a órtese indicada deve ser utilizada durante as atividades diárias ${ }^{(1,2,3,4)}$.

Os materiais descritos na literatura como os mais utilizados atualmente na construção de órteses são os termoplásticos de baixa temperatura ${ }^{(5)}$. Este material é utilizado nos atendimentos de terapia ocupacional realizados no ambulatório Bias Fortes, do Hospital das Clínicas da Universidade Federal de Minas Gerais, em Belo Horizonte. No entanto, para o tratamento de desvio ulnar, há baixa adesão ao aparelho confeccionado com este material, pois os pacientes o consideram "duro", inflexível a ponto de restringir os movimentos, e que "machuca ao fazer as coisas". A partir desta queixa, os próprios pacientes, em conjunto com os terapeutas ocupacionais, desenvolveram uma órtese construída com material alternativo (jeans), com a intenção de melhorar a adesão ao uso do aparelho.
Atualmente, quatro pacientes utilizam diariamente a órtese de jeans, principalmente durante a realização de suas atividades domésticas. Os pacientes relatam as vantagens da órtese confeccionada de material alternativo em comparação com aquela anteriormente usada, comentando que "os movimentos ficam melhores”, "o aparelho dá mais firmeza para fazer as coisas", "sinto a mão no lugar", "o alinhamento dos dedos alivia a dor", "a mão chega no lugar". Quanto ao material (jeans), os pacientes relatam que "é ótimo", é lavável, não esquenta muito e permite liberdade de movimentos, sendo esta vantagem a mais importante.

Ao colocar as articulações em posições adequadas, as órteses podem permitir que as mãos consigam movimentação funcional de maneira mais efetiva ${ }^{(5)}$. A seleção dos materiais deve incorporar as preferências individuais como fator crítico na busca dos objetivos clínicos ${ }^{(3)}$. Pôde-se verificar a importância da participação do paciente no processo de desenvolvimento da órtese.

\section{REFERÊNCIAS}

1. Feinberg JR, Trombly CA: Arthritis. In: Trombly CA: Occupational Therapy for physical disfunction. Baltimore: Williams \& Wilkins, 815-30, 1995.

2. Gilbert-Lenef L: Soft ulnar deviation splint. Journal of hand therapy 7: 29-30, 1994

3. Hammond A: Rheumatoid arthritis. In: Turner, A. et al. Occupational therapy and physical dysfunction; principles, skills and practice. 4.a ed, New York: Churchill Livingstone, 760-2, 1996.

4. Swanson AB, Pierc TD, Leonard J, Swanson GG: Orthoses for the Arthritic Hand and Wrist. In: Atlas of Orthoses and Assitive Devices. 3.a ed, Mosby, 320-1, 326-9, 1997.

5. Fess EE, Kiel JH: Imobilização do Membro Superior com Tala. In: Neistadt ME, Crepeau EB: Willard \& Spackman - Terapia Ocupacional. 9.a ed, Rio de Janeiro, Guanabara Koogan, cap 20, 2002.

JOHANNA NOORDEHOEK LUIZ FABIO MACHADO BARBOSA Departamento de Terapia Ocupacional da Escola de Educação Física, Fisioterapia e Terapia Ocupacional da Universidade Federal de Minas Gerais 


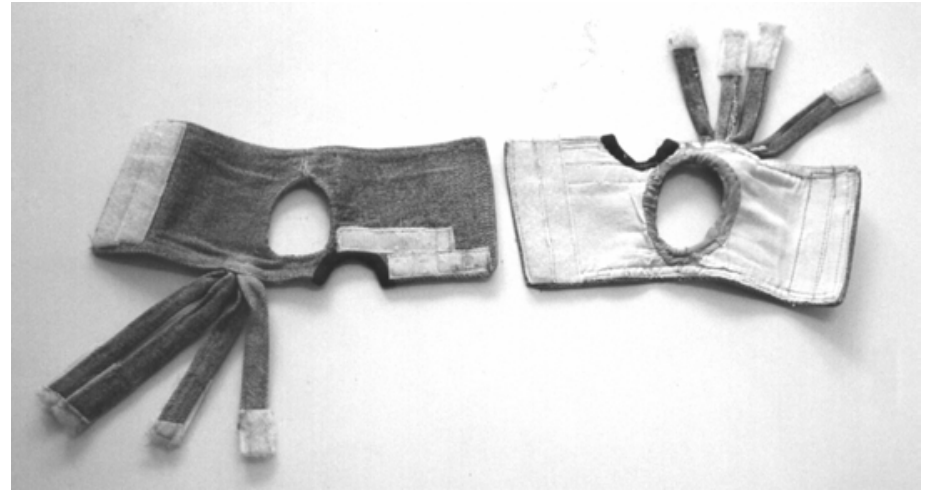

Figura 1 - Vista dianteira e ReVERSA da óRteSe de JeAns.

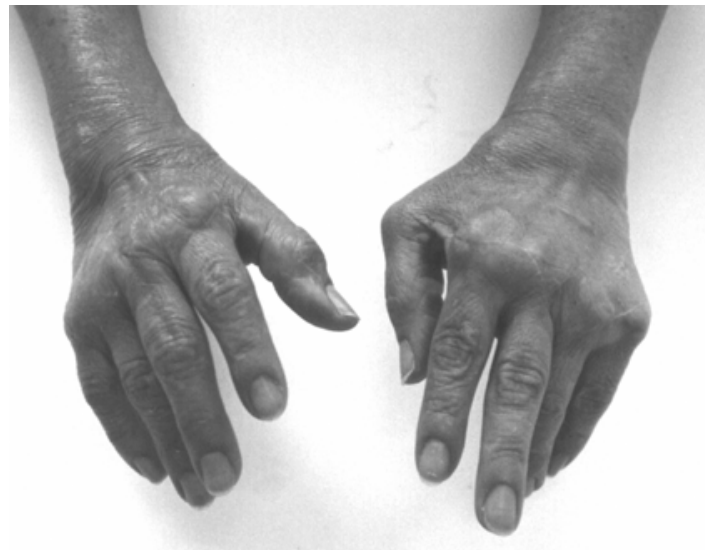

Figura 2 - Vista doRSAL dA MÃo SEM A ÓRTESE.

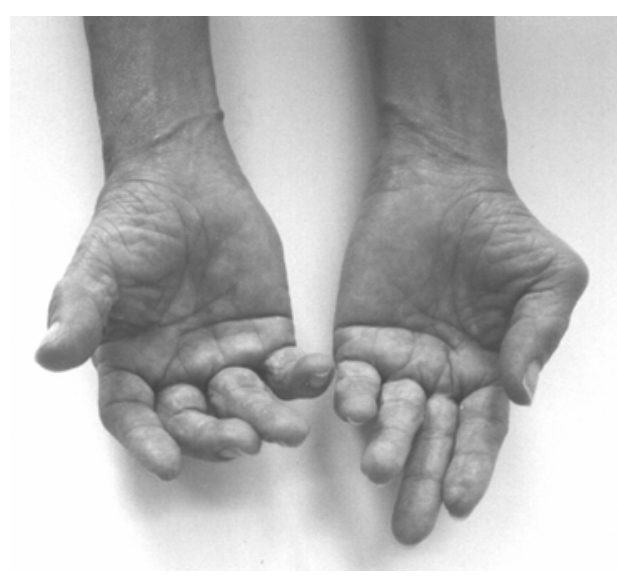

Figura 4 - Vista VENTRAL da MÃo SEM A ÓRTESE.

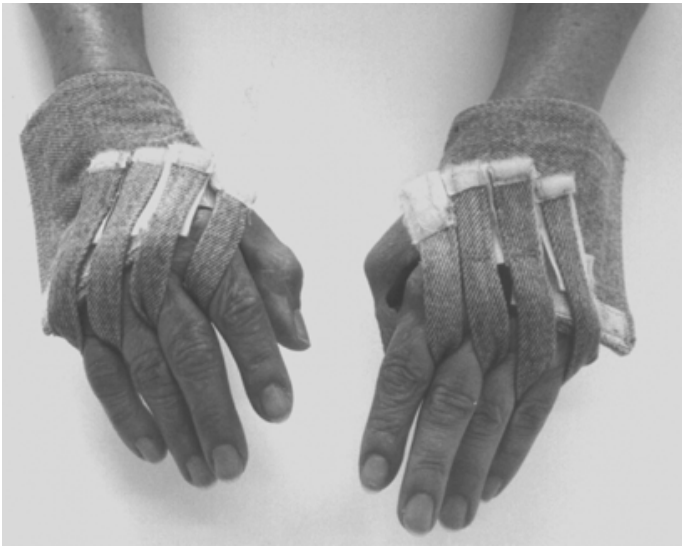

Figura 3 - Vista dorsal da mão COM A ÓRTeSE.

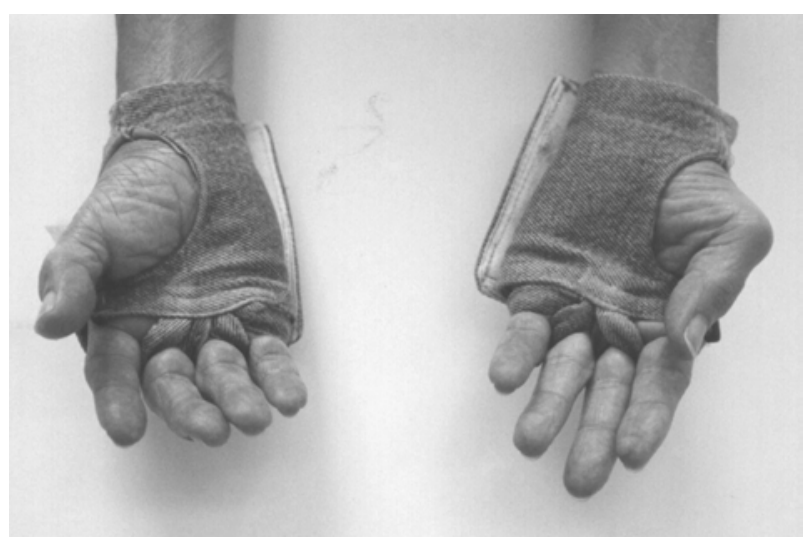

Figura 5 - Vista dORSAL dA MÃo COM A ÓRTESE. 